\title{
Editorial
}

Denis Horgan

\section{EU health policy is on the brink of a spectacular own-goal that will harm patients and hamper innovation}

https://doi.org/10.1515/cclm-2021-1100

Within a few months from now, the supply of medical tests in Europe will be drastically reduced, limiting the range of doctors' key resources for accurate patient diagnosis - and all because of a well-meaning but badly-implemented EU regulation.

The EU regulation for in vitro diagnostic medical devices (IVDR) is due to come into force on 26 May, 2022, ostensibly to raise safety for patients. But the regulatory framework on which it relies is not yet in place, condemning thousands of in vitro diagnostic tests (IVDs) to disappear from the care system - with potentially catastrophic implications for patients. The background is described in detail in the paper by Cobbaert et al. [1] in this issue of the journal.

At stake are the diagnostic tests whose results underpin more than two-thirds of clinical decisions made by caregivers in hospitals [2].

This looming predicament has triggered warnings from right across the medical world of "a cliff-edge" [3] and the concerns are felt among clinicians, patients, academics, and researchers as much as by hospitals, laboratories and companies that produce tests [4].

When the IVDR regulation was adopted, in 2017, it was already evident that new challenges would arise from the tighter requirements governing IVD development processes and the use of in-house developed tests within testing laboratories. The new rules were designed to put in place a risk-based classification system. It imposed assessment and certification requirements on thousands of medical tests. And while it granted exemptions for class $\mathrm{A}$ IVDs (lowest risk class), all class B, C and D tests have to undergo notified body assessments [1].

It was confidently expected that the necessary infrastructure and regulatory apparatus would be rapidly put in

Prof. Denis Horgan, European Alliance for Personalised Medicine, Avenue de l'Armee/Legerlaan 10, 1040 Brussels, Belgium, Phone: +386 30607 281, E-mail: denishorgan@euapm.eu place to operate the stricter regime envisaged, and a transition period was accordingly provided for. But the calculations on which it was based have proved to be woefully over-optimistic.

\section{Premature infrastructure}

There are insufficient operational notified bodies - who have to deliver the necessary certifications: of the 18 notified bodies previously functioning under the IVDD, only 6 have gained designation to operate under IVDR [3].

The infrastructure for the highest-risk tests is minimally in place - jeopardising the availability of tests in all risk classes, such as tests needed to screen the European blood supply, check cells and organs for transplantation, or manage outbreaks of infectious disease such as COVID-19.

The highest risk tests also require advise by expert panels and European reference laboratories on the evaluations of the tests that have been performed by the notified bodies, and these are not yet operational.

In consequence, massive queues have built up of test-producers and test-users in need of the necessary clearance. Meanwhile, overstretched regulators in the member states and the European Commission are struggling to approve the notified bodies whose job it is to provide clearance, with - on September data - only six so far approved, with only a further 10 who are still in the approval process. Information on implementation is lacking in many member states, as is guidance on the application of the new rules [3].

\section{Downside risks}

Without urgent remedial action and in the worst-case scenario, only $24 \%$ of the currently available IVDs may be CE-marked under the IVDR beyond the Date-of-Application for EU and global health services [3]. 
Non-availability of medical tests will seriously harm patients by preventing caregivers from making appropriate clinical decisions.

Many smaller producers of tests are particularly vulnerable, since they may not have resources to withstand the loss of revenue that will result from the delay in their sales pending certification of their products.

There is uncertainty over the consequences if a laboratory were to continue to offer an unapproved test, on the grounds that it was essential for clinical practice and there were no alternative approved tests or commercially available kits.

The uneven infrastructure will exacerbate existing inequalities in availability of tests across Europe, since manufacturers will inevitably tend to focus their certification efforts in case of necessary derogations first in the countries with the larger markets - leaving smaller (or poorer) countries less well-served.

The backlog of existing products awaiting certification may also have an adverse effect on new or emerging products, since delays and uncertainties over certification may discourage investment in development - with a negative knock-on for the EU's ambition to support innovation in medical care.

Specialty tests for genetics, virology, molecular diagnostics or cancer will be particularly vulnerable, and fewer personalised diagnostics and tests for rare diseases will be developed - or they will be developed elsewhere (the US, for instance, has a clearer regulatory framework for IVDs, as well as also offering a single market).

\section{Urgency}

The deadline for full implementation of the new rules is now too close for Europe's health services to be fully maintained.

The most commonly-required certification process usually takes around a year, with another three months for the more sophisticated tests, and as much as an additional six months for companion diagnostics.

In July 2021, certificates had not yet been issued for more than three-quarters of the medical devices produced by the Medtech Industry in Europe. In late 2021 53\% of manufacturers still do not have a contractual agreement with a notified body to assess and certify their quality management systems and IVDs under the new regime And even a framework agreement does not guarantee that the notified body can actually assess all the tests covered by the agreement in time to meet the deadline of May 2022 [3].

\section{Solutions}

The date must be modified to allow the comprehensive installation of a functioning system to ensure early diagnosis of patients, and to achieve a degree of regulatory clarity that alone can sweep away the current uncertainties enveloping the entire health sector.

The expected loss is avoidable and preventable. After all, medical laboratories are operating under stringent Quality Management Systems and ISO-guidelines (e.g. ISO 15189:2012) for decades in most EU member states. Having a viable quality management infrastructure in place to guarantee safe and effective use of medical tests, and a supportive infrastructure of quality control and interlaboratory standardisation, a modification of the legislation to allow for adequate grace periods and/or postponement to complete certification for all categories of IVDs, should be considered to safeguard the health of Europe's citizens'.

Despite calls from some EU voices for maintaining the deadline for implementation - notably from European consumers and from some health ministers anxious to ensure the probity of ineffective and unsafe Covid tests proliferating on the market - the evidence is overwhelming that patients and consumers will be negatively impacted if the May 2022 deadline is not eased.

The ball lies firmly in the court of the European institutions to agree on a solution. A simple amendment to the legislation would suffice if it provided for the rules to apply from two years after sufficient essential infrastructure, including reference laboratories and notified bodies, has been defined and declared fully functional.

Already the other major EU institutions, the Council and the European Parliament, have urged action to extend the timeframe: the EU council on June 15 urged the Commission and member states "to continue their efforts as regards the timely and adequate application of Medical Devices and IVD Regulations, in order to ensure the availability and accessibility of medical devices and IVDs in the European market" [5]. As Europe emerges from the greatest health crisis of the last century, patients would neither forgive nor forget administrations that needlessly provoke another crisis. The Commission is currently fully aware and urgently seeks solutions with all IVD-stakeholders.

A range of consultations were held by the EC in September 2021 to ensure continuity of commercial tests and of in-house developed tests [6]. With less than 8 months to go and having certified only 2,878 tests (12\%) out of the 31,067 tests intended to be certified under the 
IVDR [7], contingency plans and/or more time is needed to fix at the EU level the current situation. On October 14th 2021, the European Commission proposed a progressive roll-out of the new In Vitro Diagnostic Medical Devices Regulation to prevent disruption in the supply of these essential healthcare products 8]. In particular, the new Article 110 of the IVD Regulation provides for a transitional period until 26 May 2024 for in vitro diagnostic medical devices with a certificate issued by a notified body in accordance with the Directive prior to 26 May 2022. This transition period is extended by 1 year until May 2025. However, only $8 \%$ of devices that require a notified body certificate will benefit from this existing transitional provision. In order to address the shortage of notified body capacity, the Commission has proposed additional transitional periods for devices that have to undergo a conformity assessment involving notified bodies for the first time. The proposal differentiates between risk classes, with a transition period until May 2025 for high risk devices (class D), until May 2026 for class C devices and until May 2027 for lower risk devise (class B and A sterile). This approach aims to balance the available notified body capacity with high level of public health protection. However, this proposal from the European Commission is the first step of a legislative process requiring the agreement of all $\mathrm{EU}$ institutions. The only legally-binding outcome is the one that has been adopted and published in the EU Official Journal. Irrespective of this proposal from the European Commission, the IVD Regulation will apply in full from 26 May 2022 to CE marked in vitro diagnostic medical devices that do not require the involvement of a notified body.

The key element is that the EU regulatory system is put into place first, before the countdown starts. Only then the positive goals that the IVDR promotes, such as increased clinical evidence, transparency through the EUDAMED database, and post-market surveillance throughout the lifecycle of tests, can be accomplished for EU patients.

Author contributions: All authors have accepted responsibility for the entire content of this manuscript and approved its submission.
Competing interests: Authors state no conflict of interest. Informed consent: Not applicable.

\section{References}

1. Cobbaert C, Capoluongo ED, Vanstapel FJLA, Bossuyt PMM, Bhattoa HP, Nissen PH, et al. Implementation of the new EU IVD regulation - urgent initiatives are needed to avert impending crisis. Clin Chem Lab Med 2021;59:33-43.

2. Shotorbani K, Orr J, Landsman K. Priming the clinical laboratory for population health. The Pathologist 2020. Available from: https:// thepathologist.com/inside-the-lab/priming-the-clinicallaboratory-for-population-health [Accessed 3 Oct 2021].

3. MedTech Europe Survey Report analysing the availability of in vitro diagnostic medical devices (IVDs) in May 2022 when the new EU IVD regulation applies. Available from: https://www. medtecheurope.org/reso/urce-library/medtech-europe-surveyreport-analysing-the-availability-of-in-vitro-diagnostic-medicaldevices-ivds-in-may-2022-when-the-new-eu-ivd-regulationapplies [Accessed 30 Sep 2021].

4. Patient and consumer groups have consistently focused on the need for speedy implementation of the necessary infrastructure. Available from: https://www.eu-patient.eu/news/latest-epfnews/2020/statement-postponement-mdr-regulation/https:// www.beuc.eu/publications/beuc-x-2019-069_consumer_ concern_over_delay_of_eu_database_on_medical_devices.pdf [Accessed 11 Oct 2021].

5. Council conclusions on access to medicines and medical devices for a Stronger and Resilient EU; 2021. Available from: https://data. consilium.europa.eu/doc/document/ST-9750-2021-INIT/en/pdf [Accessed 11 Oct 2021].

6. European Commission. Medical devices - new regulations. Available from: https://ec.europa.eu/health/md_newregulations/ overview_en [Accessed 11 Oct 2021].

7. NANDO listing for IVDR 2017/746. Available from: https://ec. europa.eu/growth/tools-databases/nando/index.cfm? fuseaction=directive. notifiedbody\&dir_id=35 [Accessed 29 Sep 2021].

8. Proposal for a Regulation of the European Parliament and of the Council amending Regulation (EU) 2017/746 as regards transitional provisions for certain in vitro diagnostic medical devices and deferred application of requirements for in-house devices. Available from: https://ec.europa.eu/health/sites/ default/files/md_newregulations/docs/md_2017-746regulation_2021-amendment_en.pdf [Accessed 20 Oct 2021]. 